\title{
Bioremediation of Petroleum Hydrocarbon by using Pseudomonas Species Isolated from Petroleum Contaminated Soil
}

\author{
VIJAY KUMAR ${ }^{1}$, SIMRANJEET SINGH ${ }^{2}$, ANU MANHAS ${ }^{1}$, PRITIKA NEGI ${ }^{2}$, SOURAV SINGLA², \\ PARVINDER KAUR ${ }^{2}$, POOJA BHADRECHA ${ }^{2}$, SHIVIKA DATTA ${ }^{3}$, ARJUN KALIA ${ }^{2}$, \\ RIDHI JOSHI ${ }^{2}$, JOGINDER SINGH ${ }^{2 *}$, SITANSH SHARMA ${ }^{1}$ and NIRAJ UPADHYAY ${ }^{1}$
}

${ }^{1}$ Department of Chemistry, Lovely Professional University, Phagwara - 144411, India. Department of Biotechnology, Lovely Professional University, Phagwara - 144411, India.

${ }^{3}$ Department of Zoology, Lovely Professional University, Phagwara - 144411, India.

${ }^{\star}$ Corresponding author E-mail: simnav14@gmail.com

http://dx.doi.org/10.13005/ojc/300436

(Received: September 30, 2014; Accepted: November 21, 2014)

\begin{abstract}
A newly isolated strain Pseudomonas fluorescens (Accession number KF 279042.1) have potential in diesel degradation and can be recommended for bioremediation of sites that are contaminated with diesel. This bacterium was characterized on the basis of microbiological, biochemical and molecular analysis. Bacterial growth optimization was studied based on carbon source, nitrogen source, $\mathrm{pH}$ and temperature. The strain was selected based on its ability to show growth in medium containing diesel. In addition, optimum temperature and $\mathrm{pH}$ for increased growth by the isolate were found to be $37^{\circ} \mathrm{C}$ and $\mathrm{pH} 8.0$ indicating the maximum utilization of diesel. At the same time, production of protease and urease enzymes during the utilization of diesel was also assayed following the standard procedures.
\end{abstract}

Key words: Bioremediation; Petroleum hydrocarbons; Pseudomonas fluorescens.

\section{INTRODUCTION}

Soils contaminated with petroleum hydrocarbon such as alkanes, benzene, methylbenzene and poly-aromatic hydrocarbons (PAH) are toxic. Usually these compounds are categorized as carcinogenic substances. They cannot be easily eliminated from environment, and eventually these contaminants can leach into the groundwater systems $^{1-5}$. Consequently, oil contamination is a serious environmental problem to our living ecosystem. These components of oil are toxic to humans and wildlife in general, as it is easy to incorporate into the food chain. This fact has increased scientific interest in examining the distribution, fate and behavior of oil and its derivatives in the environment. Bioremediation is an option that offers the possibility to destroy or 
render harmless various contaminants like pesticides, hydrocarbons and heavy metals using natural biological activity. ${ }^{6-13}$

So keeping in view the above constrains, the present study was designed to screen certain bacterial isolates from diesel contaminated sites, belonging to decomposition of hydrocarbons. Current study was divided into three main parts; (1) collection of different industrial soils. (2) Isolation and characterization of strains belonging to decomposition of diesel. (3) Finally, in vitro analysis to check the effect of temperatures, $\mathrm{pH}$, concentrations of diesel on decomposition behaviour of isolate(s).

\section{MATERIALAND METHODS}

\section{Isolation from soil sample}

Bacteria were isolated from the collected soil samples by serial dilution and agar plating method. One gram of dried soil was dissolved in 9 $\mathrm{ml}$ of distilled water and mixed vigorously. Soil suspension was diluted from $10^{-1}$ to $10^{-6}$ dilutions, and from this, $10^{-5}, 10^{-6}$ dilutions were spread on sterile specific media. The inoculated plates were incubated at $37^{\circ} \mathrm{C}$ for 24 hours. Plate containing pure culture was stored at $4^{\circ} \mathrm{C}$ until for examination. ${ }^{14,15}$

\section{Characterization of the Isolates}

The isolate were characterize through molecular analysis and biochemical tests. ${ }^{14-18}$ To confirm the identity and specie of isolate, it was sent to the Ahmadabad, Gujrat for 16S rRNA molecular analysis. ${ }^{14-18}$

\section{Affects of diesel concentrations, temperature and $\mathrm{pH}$ on isolate}

The strain growing in the flask containing Kings B media containing different concentration of diesel $(2 \%, 4 \%, 6 \%, 8 \%, 10 \%)$ the flask was then incubated in shaker at $37^{\circ} \mathrm{C}$ for 24 hours After 24 hours incubation, $5 \mathrm{ml}$ sample was collected from each flask and assayed for optical density (OD) at $600 \mathrm{~nm}$ using spectrophotometer. Growth was measured in terms of OD values and the selected optimal level of diesel yields maximum growth. In a similar way, the effect of different $\mathrm{pH}(3,4,5,6,7,8$, $9,10,11$ and 12) was also studied at the best level of diesel in the medium and similarly using the best level of diesel, the effect of different temperature $\left(10^{\circ} \mathrm{C}, 20^{\circ} \mathrm{C}, 30^{\circ} \mathrm{C}, 40^{\circ} \mathrm{C}, 50^{\circ} \mathrm{C}\right)$ on growth of the isolate was also studied. ${ }^{14-18}$

\section{Utilization of diesel as sole source of carbon and energy}

To observe the possibility of utilization of diesel as carbon and energy source, the isolates were allowed to grow in King's B broth medium containing different ratios of glycerol and diesel as carbon source $(0: 100,25: 75,50: 50,75: 25$ and 100:0). After a period of incubation, growth was measured by taking the OD value. ${ }^{14-18}$

\section{Biodegradation efficiency}

Hydrocarbon (diesel) degrading activity was detected by the formation of clear zone formation around the bacterial colonies by using selective media. To further determine the biodegradation efficiency of the isolates, broths were used for testing the degradation activity. Five flasks containing $50 \mathrm{ml}$ of sterilized Kings B broth supplemented with different conc. of diesel separately and then each flask was inoculated with $1 \mathrm{ml}$ of bacterial isolates. Broth with diesel oil was treated as control. The flasks were incubated in an incubated shaker maintained at $30^{\circ} \mathrm{C}$ for 7 days. After incubation $O D$ for culture from the flask were measured at $600 \mathrm{~nm}$. OD values reflect the bacterial growth upon utilization of the hydrocarbon as a sole source of carbon. ${ }^{14-19}$

The biodegradation efficacy (BE) was calculated using the following formula, BE (\%) = $100-\left(A_{s} / A_{a c} \times 100\right)$, where $A_{s}=$ absorbance value of tested sample, $A_{a c}=$ represents the absorbance value of control samples.

\section{Enzymatic activity}

The strains were screened for extracellular enzymatic activity. For enzyme production, Pseudomonas isolates were cultivated at $37^{\circ} \mathrm{C}$ for 24 hours at $\mathrm{pH} 8.0$ in a $250 \mathrm{ml}$ Erlenmeyer flask containing $50 \mathrm{ml}$ of nutrient broth medium with optimal concentration of diesel and incubated for $24 \mathrm{hrs}$. After incubation, centrifugation was done at $3000 \mathrm{rpm}$ for $20 \mathrm{~min}$. and supernatant was obtained. The activity of protease enzymes during diesel utilization as well as in the absence of such oil in the medium was done. At the time of quantitative 
estimation of the enzymes, the growth was also measured in terms of OD values.

\section{RESULTS AND DISCUSSIONS}

\section{Identification of the isolates}

The soil samples of same site were divided into two parts, 1) sample collected from close to diesel pump and 2) samples collected from $10 \mathrm{~m}$ away from the diesel pump. Bacteria isolated from diesel contaminated soil samples using culturing techniques were allow for identification of the strains on the basis of morphology, staining, physiological and biochemical characterization (Fig. 1.). Colonies on both soil sample isolates were suspected to be belong to the genus Pseudomonas were grown on nutrient agar, Centrimide agar, Pseudomonas isolation agar and Kings $B$ agar characterized by mucoidal, shiny properties, and most of them were produce Pyocyanin and pyoverdin pigments and have a grapelike odor. Microscopic examination of each isolate showed that they were all motile, non-spore forming, gram negative and rod shape as shown in Fig.1 (3a \& b). It was observed that both isolates have same kind of traits as mentioned in Table 1 and Fig. 1. The biochemical tests mentioned under Table 1 was found similar to both isolates (named as isolate 1 and isolate 2 in whole study) Finally, these two, one isolate (isolate 1) was allow for molecular analysis where phylogenic tree was generated and final features were confirmed.

Table 1: Biochemical characteristics of the isolates

\begin{tabular}{lccc}
\hline Identification traits & Isolate $\mathbf{1}$ & Isolate 2 & Control \\
\hline Shape & Rod & Rod & Rod \\
Gram staining & Gram -ve & Gram -ve & Gram -ve \\
Motility & + & + & + \\
Indole production & + & - & - \\
Methyl red & + & - & - \\
Citrate utilization & + & + & + \\
Urease test & - & - & + \\
Oxidase test & + & + & + \\
Catalase test & + & + & + \\
\hline
\end{tabular}
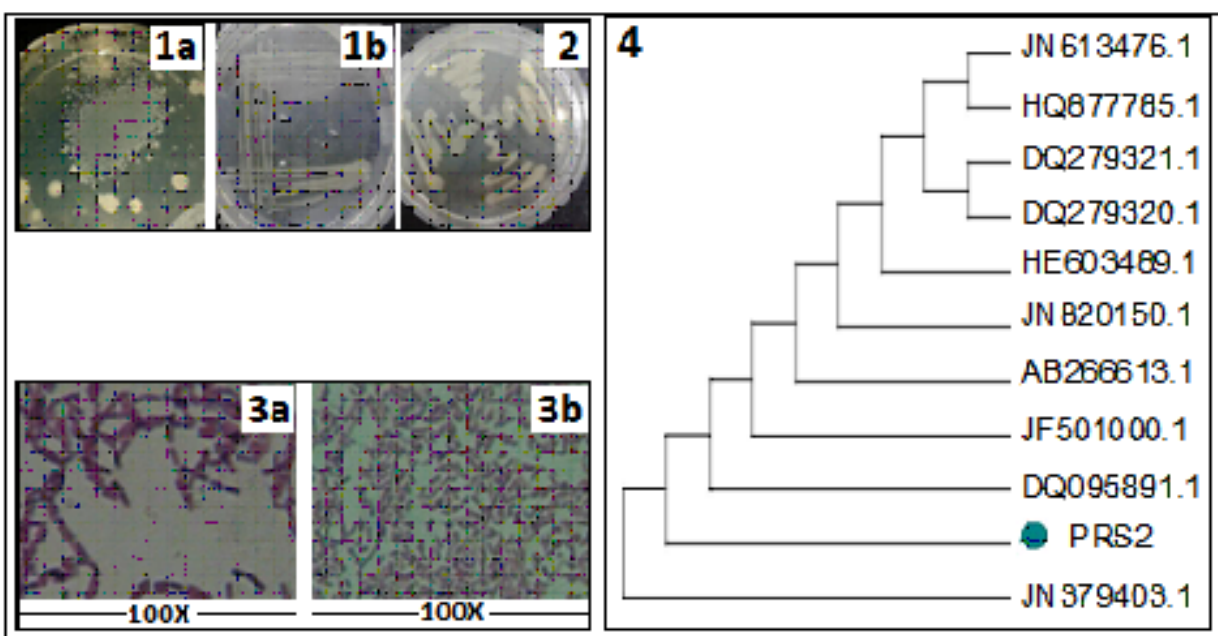

Fig. 1: Charaterization of isolate. Fig. (1a, 1b, 2, 3a \& 3b). Growth of isolate, on Pseudomonas isolation agar (1a \& b), on Kings B agar (2), microscopic examination of isolate ( $3 a$ \& b). Fig. 4. Phylogenetic Tree of isolate 1 

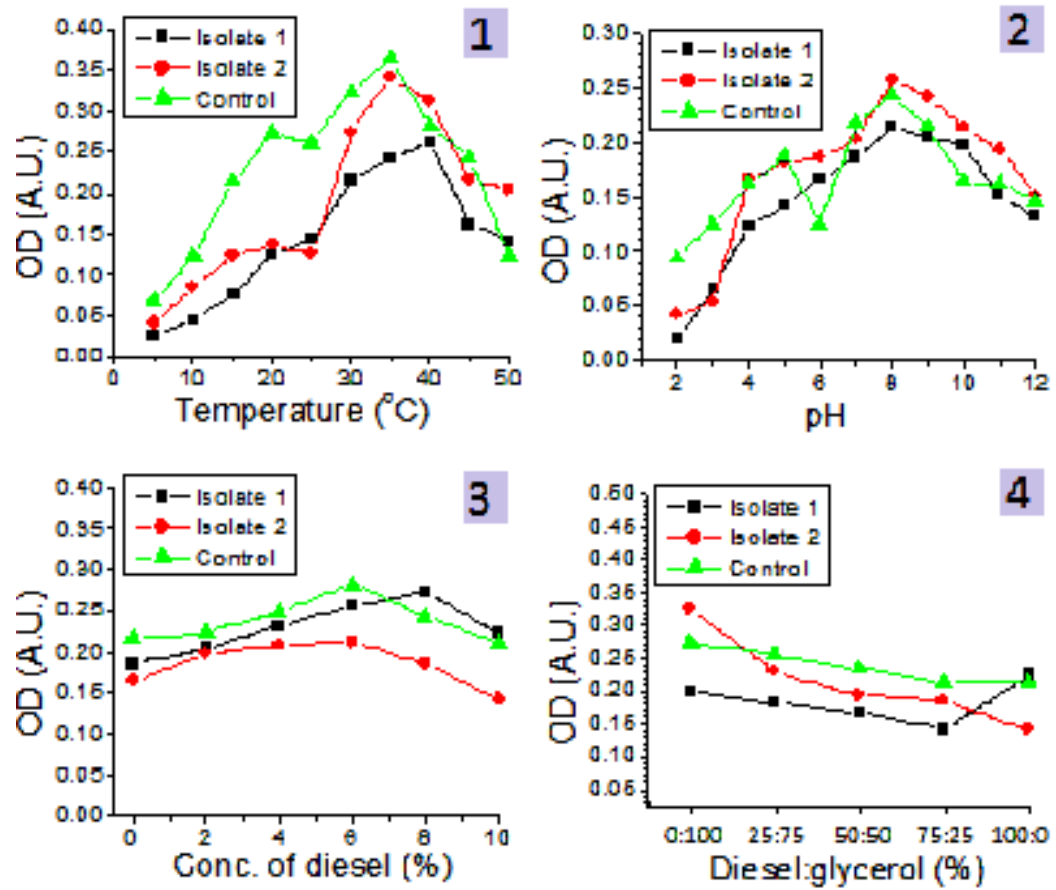

Fig. 2: Effect of temperature (1), pH (2), concentrations of diesel (3), and diesel:glycerol

(4) on isolate 1 and isolate 2 at $600 \mathrm{~nm}$ as compared to control (P. fluorescens).

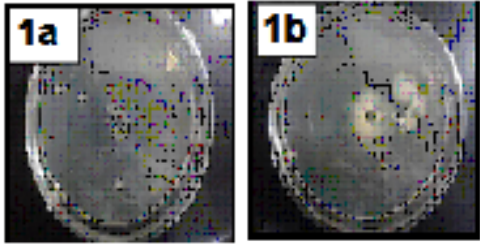

2

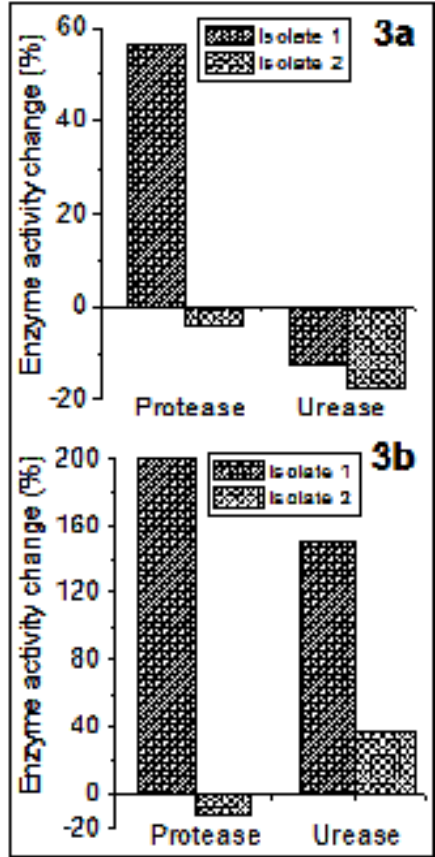

Fig. 3: Biodegradation Efficiency (1a and 1b), Biodegradation (\%) and \% change in enzyme (protease and urease) activity. Fig. (1a \& 1b). Biodegradation Efficiency of isolate 1 and isolate 2 on diesel.

Fig. (2). Biodegradation (\%) of isolate Pseudomonas fluorescens or isolate 1 as a function of incubation time (days). Fig. (3a \& 3b). \% change in enzyme (protease and urease) activity at 600nm; with diesel (1) and without diesel (2) as compared to control (P. fluorescens). 
The extraction of DNA from bacterial isolates, PCR amplification, construction of $16 \mathrm{~S}$ rDNA clone libraries, Sequencing and phylogenetic analysis were performed as per detailed procedures given by Sun et al., "2010". The culture was found to be Pseudomonas fluorescens strain (PRS2), 16S ribosomal RNA genes (GenBank Accession Number: DQ095891.1) based on nucleotide homology and phylogenetic analysis (Fig. 1 (2))

\section{Effect of diesel concentrations, temperature and $\mathrm{pH}$}

To determine the ability of isolate to utilize various concentration of diesel using broth culture. The strain was growing in the flask containing Kings $B$ media plus different conc. of diesel and incubated at $37^{\circ} \mathrm{C}$ in shaker for 24 hours Result showed that isolate were grown well in all concentration of diesel relative to control. It can be seen that maximum utilization of the diesel by the isolates took place at $8 \%$ which indicates that $8 \%$ is the optimum concentration of growth. Although, growth was at $2 \%, 4 \%, 6 \%$ and $10 \%$ concentrations of diesel, was relatively less. Similarly, effect of temperature and pH were also done, as shown in Fig. 2 (1 \& 2), which showed that the optimum temperature for better grow $\left(8 \%\right.$ of diesel level) was $35^{\circ} \mathrm{C}-40^{\circ} \mathrm{C}$, and $\mathrm{pH}$ was 8.0 .

Also both isolates have exhibited effective utilization of diesel when supplemented the diesel as a sole source of carbon than glycerol Fig. 2 (4). All isolates shows better utilization of diesel than glycerol and exhibited better growth as compare to glycerol as shown in Fig. 2 (4).

\section{Biodegradation Efficiency on diesel}

The biodegradation activity of isolate 1 in the agar plate assay was performed on Kings B and Pseudomonas isolation agar resulting clearing zone produced on the agar supplemented with diesel [Fig. 3 (1a \& 1b)]. The biodegradation efficiency of diesel oil by $P$. fluorescens increased in efficiency from the first two or three days of incubation which showed rapid degradation in the first three days, with means of $54 \%$ of biodegradation efficacy (Fig. 3 (2)). The biodegradation efficiency decreased after the 5 th $^{\text {th }}$ day, mean percentage of biodegradation efficacy decreased to less than $40 \%$ as shown in (Fig. 3 (2)).

Isolate diesel utilization efficiency and enzyme production capacity results showed that the three isolates exhibited greater protease and urease activity. The order of efficiency of protease isolate $2>$ isolate $1>$ control ( $P$. fluorescens). The orders of efficiency of producing urease isolate $1>$ control ( $P$. fluorescens) > isolate 2. Fig. 3 (3a \& 3b) has dictated that in the presence of $25 \%$ diesel the enzyme activity of isolate $1 \& 2$ decreased, but isolates 1 has shown $60 \%$ increase in protease activity as compared to control. More interestingly, as compared to control, in the absence of diesel (25\%), isolates 1 has shown $200 \%$ and $150 \%$ increments in protease and urease enzymatic activities, whereas isolates 2 has shown $14 \%$ decrease and $40 \%$ increment in protease and urease enzymatic activities.

\section{CONCLUSION}

This study investigated the biodegradation of diesel oil by Pseudomonas and the activities of soil enzymes in degradation. The soil enzymes activities from Pseudomonas (dehydrogenase, catalase, urease and polyphenol oxidase) under the different conditions were investigated. The bacterial stains screened showed good abilities of promoting degradation. In this study, it was showed that the degradation results were quite different as the different treatments were applied. The experiments showed that the activity of soil urease was an important indicator of the crude oil polluted degree. Further, it is indicated that the bacteria have the different utilization ability for different hydrocarbon carbon sources. In addition, excellent exhibition of plant growth promoting properties is an advantage of new strain.

\section{REFERENCES}

1. Ahmed, Z.; Song, J.H. Biotech 2011, 1(2), 111-116.

2. Chikere, C.N.; Okpokwasili, G.C.; Chikere,
B.O. 3Biotech 2011, 3(1), 117-138.

3. Mishra, P.K.; Mukherji, S. 3 Biotech 2012, 2(4), 301-310. 
4. Arora, P.K.; Jain, R.K. 3 Biotech 2013, 3(1), 29-32.

5. Li, G.; Huang, W.; Lerner, D.N.; Zhang, X. Water Resour. 2000, 34, 3845-3853.

6. Kumar, V.; Upadhyay, N.; Wasit, A.B.; Simranjeet, S.; Parvinder, K. Current World Environment 2013, 8(2), 313-318.

7. Kumar, V.; Upadhyay, N.; Singh, S.; Singh, J.; Kaur, P.; Current World Environment 2013, 8, 469-473.

8. Kumar, V.; Upadhyay, N.; Kumar, V.; Kaur, S.; Singh, J.; Singh, S.; Datta, S. J. Bio. Env. Sci. 2014, 5, 111-120.

9. Kumar, V.; Upadhyay, N.; Kumar, V.; Sharma, S. J. Bio. Env. Sci. 2014, 5,149-165.

10. Prasad, R.; Upadhyay, N.; Kumar, V., Microchem. J. 2013, 111, 91-97

11. Margesin, R.; Schinner, F.; Zimmerbauer, A.
Chemosphere 2000, 40, 339-346.

12. Aswathy, A.J.; Jasim, B.; Jyothis, M., Radhakrishnan, E.K.; Biotech 2013, 3(3), 219-224.

13. Duarah, I.; Deka, M.; Saikia, N.; Boruah, H.P.D.; Biotech 2013, 1(4), 227-238.

14. Atlas, R.M.; Int. Biodeteri. 1995, 35, 317-327.

15. Leahy, J.G.; Colwell, R.R. Micro. Rev. 1990, 53, 305-315.

16. Modi, V.V.; Patel, R.N.; Appl. Microbiol. 1968, 16, 172-173.

17. Johnsen, A.R.; Wick, L.Y.; Harms, H. Environ. Pollut. 2005, 133, 71-84.

18. Caballero, A.R.; Morean, J.M.; Engel, L.S.; Marquart, M.E.; Hill, J.M.; Callaghan, R.J. Anal. Biochem. 2001, 290, 330-337.

19. Himelbloom, B.H.; Hassan, H.M. Appl. Environ. Microbiol. 1986, 51, 418-421. 